\title{
ACCESS TO HEALTHCARE IN RUSSIA: A PILOT STUDY IN EKATERINBURG
}

\author{
Natalia Antonova
}

Institute for Social and Political Sciences, Ural Federal University, named after the first President of Russia Boris Yeltsin, Ekaterinburg, Russia

\section{SUMMARY}

Aim: The aim of the study was to analyze accessibility of medical assistance in Russian polyclinics (a case study of the city of Ekaterinburg).

Methods: The research included an anonymous survey of patients in five polyclinics of Ekaterinburg $(\mathrm{N}=500)$ conducted by applying a specially developed standardised interview.

Results: The following factors of medical care accessibility were analyzed: the patient's financial status and administrative and managerial resources of medical institutions. Medical aid in polyclinics is provided within the framework of the Compulsory Medical Insurance Programme. $72 \%$ of the patients polled, however, had to pay for medical services. In order to pay less for medical services and to obtain services faster patients use informal payments: they either pay their doctors directly $(4 \%)$ or make gifts $(58 \%)$. Low-income population groups refuse to pay for medical services or to make gifts to the medical staff. They also tend not to follow their doctors' recommendations. The most significant indicators of the organizational and managerial work of a medical institution which limit accessibility are the following: queues in front of doctors' offices (41\%) and difficulties with making appointments (17\%).

Conclusions: To solve the problem of medical aid accessibility in the Russian state healthcare system, it is necessary to develop information and reference materials for patients available in every polyclinic listing the terms of provision of free medical aid and types of free medical services. The difficulties to obtain medical services could be resolved at the management level by using the material and human resources of the administration of medical institutions.

Key words: access to healthcare, system of compulsory medical insurance, incomes of population, medical services organization

Address for correspondence: N. Antonova, Institute for Social and Political Sciences, Ural Federal University, 51 Lenin st., 620083 Ekaterinburg, Russia. E-mail:n-tata@mail.ru

http://dx.doi.org/10.21101/cejph.a3942

\section{INTRODUCTION}

The accessibility of healthcare is one of the basic problems of the healthcare system in modern Russia. Modernization of this system was based on the transition from the state system of medical services to a budget-based and private insurance system. Thus, the problems of accessibility of healthcare resurfaced as a matter of current public interest.

The World Medical Assembly (WMA) Statement on Access to Health Care was adopted by the 40th WMA in Vienna, September 1988 (1). As stated in the declaration, access to healthcare depends on the balance of state resources and medical resources. The problem of access to healthcare is also touched upon in the Convention for the Protection of Human Rights and Dignity of the Human Being with regard to the Application of Biology and Medicine signed in 1997 (2).

Access to healthcare in the Russian system of compulsory medical insurance should comply with patients' rights established in the Constitution of the Russian Federation (3), in the Federal Laws on Compulsory Medical Insurance in the Russian Federation and on the Fundamentals of Public Health Protection in the Russian Federation $(4,5)$. The essence of compulsory medical insurance is based on the concept that any individual with the citizenship of the Russian Federation can get access to medical care and medical supplies for free, in accordance with the state-guaranteed Programme on types and amounts of healthcare financed by means of compulsory medical insurance.

One of the core principles of the compulsory medical insurance system is the per capita principle ("money follows the patient"). However, at the moment it is not sufficiently developed since the mechanism is still quite vague and underdeveloped. Another problem is that after a patient is treated, it takes a long time before the medical institution will be paid for the services. Furthermore, according to the Compulsory Medical Insurance Programme, the required amount of money to be spent on one patient in 2015 is 8,260 roubles (about 120 dollars). However, this amount can hardly cover the real medical expenses. In order to get fast and high quality medical service patients have to make additional payments either formal, through the polyclinic's cash register, or informal by paying the doctor directly. The work of some polyclinics is organized in such a way that it limits the population's access to medical services (shortages of medical staff, waiting lists etc.). Therefore, the question of accessibility of medical services as one of the most challenging problems faced by the Russian healthcare system is understood as availability of opportunities to obtain different types of medical aid. 


\section{MATERIALS AND METHODS}

In 2008, we carried out a sociological study on the adult population of the city of Ekaterinburg $(\mathrm{N}=500)$. The opinion poll (questionnaire) was carried out in the polyclinics which are a part of the system of compulsory medical insurance. The distribution of the respondents reflects the age/gender makeup of the population. According to the Federal State Statistics Service, Ekaterinburg population comprises $56 \%$ of women and $44 \%$ of men. The age composition of the city's population is the following: the employable population accounts for $61 \%$, of them residents aged 18 to 30 make up $19 \%$ and senior residents $20 \%$. This research used the method of quota sampling: the percentage of men and women corresponded to the gender makeup of Ekaterinburg population with the proportional age quotas for men and women.

While choosing from different medical institutions, we based our analysis on the results of expert interviewing. The experts were specialists of the Territorial Compulsory Medical Insurance Fund. In different districts of the city five polyclinics were chosen; 100 people were polled in each. Respondents were selected according to sex/gender quotas (out of 100 respondents in each polyclinic there were 56 women, 11 of them under 30 years of age, 34 women from 30-59, and 11 over $60 ; 44$ men respondents, 9 of them under 30 years of age, 26 men from 30-59, and 9 over 60 . The survey was anonymous so the respondents did not have to disclose their identity.

\section{RESULTS}

As stated above, 500 patients were polled. The patients' gender distribution was $44 \%$ of males, and $56 \%$ of females; the age groups were as follows: $20 \%$ of people under $30,60 \%$ of people from $30-59$, and $20 \%$ of people aged 60 and over (Table 1).

The respondents evaluated their financial position as follows: $70 \%$ consider their incomes to be at the middle rate, $5 \%$ high-rated and $25 \%$ low-rated their incomes.

Our research has found two factors which influence access to medical services: the income of the population sample and administration of medical service organizations.

\section{Population Income as a Factor Influencing Access to Medical Services}

This factor is related to the patients' income level and their expenses for medical services. More than a half of the patients had to pay for medical services $(72 \%)$. Every third had to pay
30-50 US Dollars (from 1,000-1,500 Russian Roubles). 75\% of the patients said the medical service costs were high. None of the respondents with low-level incomes paid for medical services: they said that they had refused chargeable medical services offered by the doctor. The level of information about free medical services appeared not to be very high: $55 \%$ of respondents stated that no such information had been provided.

The research results show that low-income patients follow their doctors' instructions less frequently than others (Table 2).

The main reason for not following the doctor's recommendations on diagnostics and cure was said to be a lack of money for the low-income groups; for the groups of middle and high income levels, the main reason mentioned was a lack of time.

To deal with the problem of inaccessibility of medical services patients resort to the practice of informal payments. Based on the conceptual analysis presented in the works devoted to corruption in healthcare (6-9), we propose the following definition of informal payments: informal payments are direct payments, in cash or in other form, of some social groups to other social groups. (These may be money, gifts, or services).

Russian patients use direct payments to medical staff, which is cheaper than to pay formally through the polyclinic's cash register (4\%), and 58\% use gifts for the services rendered (bottle of cognac, box of sweets, jar of coffee etc.).

Most often, the following kinds of services are paid for: diagnostic examination without a prior appointment; appointment with a doctor in the time convenient for the patient; dental services; physiotherapy services; massages; medical certification without any symptoms; and special medical certificates. The list is by no means exhaustive.

Informal payment in the form of a gift, according to the results of the research, depends on a number of factors. First, prone to this form are patients before surgery and patients with chronic diseases. Secondly, the intention to express gratitude to the doctor usually occurs after the treatment has been successfully finished. Thirdly, the patient uses a gift in order to shorten the waiting time for obtaining the service.

\section{Administration of a Medical Organization as a Factor Influencing Access to Healthcare}

The factors related to medical centres were included in this section. We asked the patients to characterize the problems related to consulting medical specialists (Table 3 ).

When visiting a medical clinic, a patient can refuse any healthcare. Our research shows that one-third of the people polled faced such a situation. The reasons for refusal could be the absence of a specialist (23\%), and difficulties with diagnostics (15\%). Table
Table 1. Sex and age distribution of the respondents

\begin{tabular}{|l|c|c|c|c|}
\hline \multirow{2}{*}{} & \multicolumn{2}{|c|}{ Male } & \multicolumn{2}{c|}{ Female } \\
\cline { 2 - 5 } & $\mathbf{N}$ & $\%$ & $\mathbf{N}$ & $\%$ \\
\hline Under 30 & 44 & 20 & 56 & 20 \\
\hline 30-59 years old & 132 & 60 & 168 & 60 \\
\hline 60 or over & 44 & 20 & 56 & 20 \\
\hline Total & 220 & 100 & 280 & 100 \\
\hline
\end{tabular}

Table 2. Following doctors' instructions on diagnostics and cure by patients (\%)

\begin{tabular}{|l|c|c|c|}
\hline & Low-income & Middle-income & High-income \\
\hline Follow completely & 10 & 60 & 70 \\
\hline Follow partially & 60 & 30 & 20 \\
\hline Do not follow & 30 & 10 & 10 \\
\hline Total & 100 & 100 & 100 \\
\hline
\end{tabular}


Table 3. Problems with patients reception

\begin{tabular}{|c|c|c|}
\hline Problems & Female $(\%)^{*}$ & Male (\%) \\
\hline Slow reception at the doctors' office & 56 & 41 \\
\hline Doctor's reluctance to treat the patient & 23 & 17 \\
\hline Problems with making an appointment & 12 & 9 \\
\hline Time interval at reception & 10 & 7 \\
\hline Doctor is not able to cope with the number of patients & 9 & 6 \\
\hline Doctor prescribes a limited number of medical drugs & 9 & 6 \\
\hline Doctor uses obscene words while communicating with the patient & 6 & 4 \\
\hline Difficult to say & 13 & 10 \\
\hline Total & 156 & 100 \\
\hline
\end{tabular}

${ }^{*}$ The total is over $100 \%$ because one respondent could choose several options.

4 shows how the problem of getting healthcare after refusal was solved by the patients.

We asked the respondents to use a 5-point scale to assess the indicators of medical aid organization as a factor of accessibility of medical services (Table 5).

According to the patients surveyed, the opening hours of the registration office are organized best of all. The registration office is responsible for the organization of regular appointments and urgent appointments; timely and efficient regulation of the flow of patients; and filling and storage of medical cards. High scores were also given to other indicators: the polyclinic staff levels (3.8); polyclinic opening hours (3.7); diagnostic facilities (3.6); and working hours of doctors (3.4).

In general, Ekaterinburg patients assess the accessibility of healthcare quite high. The most typical commentary in the assessment questionnaire was "It could be worse".

Table 4. Steps taken by patients to get medical assistance

\begin{tabular}{|l|c|}
\hline Actions & $\%$ \\
\hline Did nothing & 60 \\
\hline $\begin{array}{l}\text { Applied to a state medical institution and obtained paid } \\
\text { medical assistance }\end{array}$ & 18 \\
\hline Applied to a private medical institution & 12 \\
\hline $\begin{array}{l}\text { Applied to a state medical institution and obtained free } \\
\text { medical assistance }\end{array}$ & 10 \\
\hline Total & 100 \\
\hline
\end{tabular}

Table 5. Assessment of indicators of medical aid organization in polyclinics ( $5=$ most accessible, 1 = least accessible)

\begin{tabular}{|l|c|}
\hline Indicators & Average score \\
\hline Opening hours of the registration office & 4.1 \\
\hline Availability of the required specialists & 3.8 \\
\hline Opening hours of the medical institution & 3.7 \\
\hline Diagnostic facilities of the medical institution & 3.6 \\
\hline Working hours of the doctors & 3.4 \\
\hline
\end{tabular}

\section{DISCUSSION}

We focused our research on whether the accessibility of medical care is influenced by population incomes and by medical service organization, i.e. administration, in certain medical centres.

According to the state-guaranteed Programme, medical services in polyclinics should be provided for free. However, more than half of the patients admitted that they had to pay for healthcare services such as ultrasound, fibrogastroscopy, electrocardiogram, and X-rays.

Our results are supported by the research results obtained by our colleagues from other regions of Russia. The latest surveys of the patients' expenses for medical care show that the expenses make up to $40-45 \%$ of all expenditures for medical services. Over $50 \%$ of patients pay for healthcare in hospital, $30 \%$ for polyclinic out-patient treatment, and $65 \%$ for dentistry (10). Practically unavailable are such medical services as consultations with specialists, surgery services and high-tech examinations. Patients have to deny healthcare because they cannot pay for it.

There is a long waiting list for a number of services. Doctors should inform patients about the possibility to get healthcare for free. However, every third patient asserted that nobody had informed them about the ways of obtaining free service. Paidfor healthcare services are often replacing free ones, which are state-guaranteed. This can be explained by the fact that there are not enough direct guarantees for providing healthcare and there is no list of free medical services available.

In order to obtain medical services without waiting, patients resort to informal payments: by paying the medical staff directly and by giving gifts. This practice is allegedly typical also for other post-socialist countries: Bulgaria (11), Romania (12), and Hungary (13). At the same time low-income groups of the population refuse to make informal payments or to use paid medical services and they also choose not to follow the doctor's recommendations more often than other groups of patients.

However, the Compulsory Medical Insurance Programme allows Russian doctors on average only ten to twelve minutes to consult one patient. Such heavy time regulations cause difficulties in organization of medical assistance and beside others represent an important factor in the population's access to medical services.

On the whole, accessibility of healthcare is influenced by the income level of the population. Low-income groups have to refuse chargeable healthcare services and they rarely follow treatment 
recommendations. They also refuse to provide presents to medical staff as a form of gratitude.

Almost every fourth respondent pointed out that the doctors are often inattentive and indifferent. However, the professional burnout syndrome is typical for doctors as a professional group.

The qualifications of medical clinic staff represent some of the essential indicators of access to healthcare. Specialists as surgeons, gastroenterologists, cardiologists, gynaecologists, neuropathologists, urologists, and endocrinologists are considered to be difficult to access.

Patients declining medical attention represent another problem in access to healthcare. The results of our study show that the overwhelming number of patients refused to pay for services and thus undertook no actions to get the required medical services. This indicator shows that for this group of patients their health loses its value.

Some fears concerning access to healthcare also affect the able-bodied population. They tend to ask for medical services more rarely, and more often get it on conditions of full or partial compensation. This has an impact on the mortality rates of the working population.

In spite of the problems described above, patients in general appreciated the organization of polyclinics work - a crucial factor for accessibility of medical care.

\section{CONCLUSION}

The results of our research show the inefficiency of the Russian healthcare system in making medical services accessible to the population.

Firstly, patients are forced to pay for services which are included in the Compulsory Medical Insurance Programme. To reduce the amount of payments and to obtain the service faster, patients resort to the practice of informal payments. Solution of this problem could be the development of information and reference materials for patients available in every polyclinic listing the terms of provision of free medical aid and types of free medical services. Another way to deal with this problem is the involvement of citizens in paying medical insurance premiums, which allow expand the range of medical services included into the insurance package.

Secondly, the lack of accessibility of some medical services caused by the organization of work in polyclinics could be resolved at the management level by using the material and human resources of the administration in medical institutions. For instance, it could be effective to organize a surveillance system to regulate and redistribute current flows of patients.

However, it will be essential to monitor accessibility of medical care and deal with such problems on the national level as well as on the level of particular medical institutions in the future.

\section{Acknowledgements}

This research was conducted at the Ural Federal University (named after the first President of Russia Boris Yeltsin), and supported by the Russian Fund for the Humanities (project no. 08-03-83309a/u).

\section{REFERENCES}

1. WMA Statement on access to health care. Adopted by the 40th World Medical Assembly, Vienna, Austria, September 1988 and revised by the 57th WMA General Assembly, Pilanesberg, South Africa October 2006 [Internet]. Ferney-Voltaire: World Medical Association; 2016 [cited 2015 Jan 22]. Available from: http://www.wma.net/en/30publications/10policies/ a6/index.html.

2. Convention for the protection of human rights and dignity of the human being with regard to the application of biology and medicine: convention on human rights and biomedicine. CETS No.164 [Internet]. STRASBOURG Cedex: Council of Europe; 4.4.1997 [cited 2015 Jan 22]. Available from: https://rm.coe.int/CoERMPublicCommonSearchServices/Dis playDCTMContent?documentId=090000168007 cf98.

3. Constitution of the Russian Federation. Moscow: The Russian Federation; December 12, 1993.

4. Federal Law of 29.11.2010 N 326-Ф3 amended on 01.12.2014 on Compulsory Medical Insurance in the Russian Federation. (In Russian).

5. Federal Law of 21.11.2011 N 323-Ф3 amended on 31.12.2014 on the Fundamentals of Public Health Protection in the Russian Federation, the amended and revised version applies after 01.01.2015. (In Russian.)

6. Lewis M. Informal payments and the financing of health care in developing and transition countries. Health Aff (Millwood). 2007 JulAug;26(4):984-97.

7. Shishkin S, Bogatova T, Potapchik Y, Chernets V, Chirikova A, Shilova L. Informal out-of-pocket payments for health care in Russia. Moscow: Moscow Public Science Foundation; Independent Institute for Social Policy; 2003. (In Russian.)

8. Gaal P, Belli PC, McKee M, Szocska M. Informal payments for health care: definitions, distinctions, and dilemmas. J Health Polit Policy Law. 2006 Apr;31(2):251-93.

9. Cohen N. Informal payments for health care-the phenomenon and its context. Health Econ Policy Law. 2012 Jul;7(3):285-308.

10. Vishnevsky A, Kuzminov Y, Shevsky V, et al. Russian health care system: how to deal with recession. Moscow: The Higher School of Economy Press; 2006. (In Russian.)

11. Balabanova D, McKee M. Understanding informal payments for health care: the example of Bulgaria. Health Policy. 2002 Dec;62(3):243-73.

12. Stan S. Neither commodities nor gifts: post-socialist informal exchanges in the Romanian healthcare systém. J R Anthropol Inst. 2012 Mar; 18(1):65-82.

13. Gaal P, Evetovits T, McKee M. Informal payment for health care: evidence from Hungary. Health Policy. 2006 Jun;77(1):86-102.

Received July 19, 2013

Accepted in revised form March 1, 2016 